\title{
Opioid agonist treatment dosage and patient- perceived dosage adequacy, and risk of hepatitis C infection among people who inject drugs
}

\author{
Andreea A. Artenie MSc, Nanor Minoyan MSc, Brendan Jacka PhD, Stine Høj PhD, Didier Jutras-Aswad MD MSc, \\ Élise Roy MD MSc, Lise Gauvin PhD, Geng Zang MSc, Julie Bruneau MD MSc
}

- Cite as: CMAJ 2019 April 29;191:E462-8. doi: 10.1503/cmaj.181506

See related article at www.cmaj.ca/lookup/doi/10.1503/cmaj.190430

\begin{abstract}
BACKGROUND: Opioid agonist treatment is considered important in preventing acquisition of hepatitis C virus (HCV) among people who inject drugs; however, the role of dosage in opioid agonist treatment is unclear. We investigated the joint association of prescribed dosage of opioid agonist treatment and patient-perceived dosage adequacy with risk of HCV infection among people who inject drugs.
\end{abstract}

METHODS: We followed prospectively people who inject drugs at risk of acquiring HCV infection (who were RNA negative and HCV-antibody negative or positive) in Montréal, Canada (2004-2017). At 6-month, then 3-month intervals, participants were tested for HCV antibodies or RNA, and completed an intervieweradministered behavioural questionnaire, reporting the following: current exposure to opioid agonist treatment (yes/no), pre- scribed dosage either high (methadone $\geq 60 \mathrm{mg} / \mathrm{d}$ or buprenorphine $\geq 16 \mathrm{mg} / \mathrm{d}$ ) or low, and perceived dosage adequacy (adequate/inadequate). We then assigned participants to 1 of 5 exposure categories: no opioid agonist treatment, high dosage of opioid agonist treatment perceived to be adequate, high dosage perceived to be inadequate, low dosage perceived to be adequate or low dosage perceived to be inadequate. To estimate associations between categories of opioid agonist treatment dosage and incident HCV infection, we conducted Cox regression analyses, adjusting for multiple confounding factors.

RESULTS: Of 513 participants (median age $35.0 \mathrm{yr}, 77.6 \%$ male), 168 acquired HCV over 1422.6 person-years of followup (incidence 11.8/100 person-years, 95\% confidence interval [Cl] 10.1-13.7). We observed a gradient in the relative risks of HCV infection across categories of opioid agonist treatment dosage. Compared with people who inject drugs not receiving opioid agonist treatment, adjusted hazard ratios were $0.43(95 \% \mathrm{Cl} 0.23-$ 0.84 ) for those receiving high dosages perceived to be adequate, $0.61(95 \% \mathrm{Cl}$ 0.25-1.50) for those receiving high dosages perceived to be inadequate, 1.22 (95\% Cl 0.74-2.00) for those receiving low dosages perceived to be adequate and 1.94 (95\% Cl 1.11-3.39) for those receiving low dosages perceived to be inadequate.

INTERPRETATION: Risk of HCV infection varies considerably according to dosage of opioid agonist treatment and patientperceived adequacy, with associations indicating both protective and harmful effects relative to no exposure to opioid agonist treatment. $\mathrm{n}$ North America, rising incidence of hepatitis C virus (HCV) has tracked the opioid epidemic. From 2004 to 2014, a twofold increase in the annual incidence of acute HCV infection was documented in the United States, mirroring increases in treatment admissions characterized by opioid injection throughout the same period. ${ }^{1}$ In Montréal, Canada, our group documented that injection of prescription opioids tripled during 2004-2009 among people who inject drugs followed in the Montreal Hepatitis $C$ Cohort (HEPCO), and this practice was linked to a nearly twofold greater risk of HCV infection relative to injection of other drugs. ${ }^{2}$

Pharmacotherapy with opioid agonist treatment, the recommended first-line treatment for opioid use disorder, ${ }^{3}$ can prevent
HCV infection, with an estimated average risk reduction of $50 \% .{ }^{4}$ The role of dosage of opioid agonist treatment in moderating this relation is unclear, however. ${ }^{4}$ Higher dosages ( $\geq 60 \mathrm{mg} / \mathrm{d}$ for methadone and $\geq 12-16 \mathrm{mg} / \mathrm{d}$ for buprenorphine), which are typically recommended by clinical practice guidelines for the management of opioid use disorders, ${ }^{3,5-7}$ are more effective in promoting treatment retention and reducing withdrawal and illicit opioid use. ${ }^{8-11}$ Increasing evidence also highlights the importance of patients' subjective perceptions of their dosage of opioid agonist treatment in influencing treatment outcomes, irrespective of prescribed dosage. Perceptions of adequate dosage have been linked to reduced opioid craving and poly-drug use, ${ }^{12}$ greater treatment adherence ${ }^{13}$ and 
willingness to continue treatment. ${ }^{14}$ Yet, many patients receive dosages lower than those considered clinically optimal or dosages that they perceive to be inadequate. ${ }^{14-16}$

In the context of an ongoing global movement to eliminate HCV as a public health threat by $2030,{ }^{17}$ and in light of evidence that scale-up of opioid agonist treatment will be central to achieving this goal, ${ }^{18}$ this study seeks to improve our understanding of how to optimize provision of opioid agonist treatment for the prevention of HCV transmission. We aimed to investigate the joint association of prescribed dosage of opioid agonist treatment and patientperceived dosage adequacy with the risk of HCV infection among people who inject drugs.

\section{Methods}

\section{Study design and sample}

We used observational data collected in HEPCO, a prospective cohort established in Montréal in 2004 to assess determinants of HCV infection among people who inject drugs. Our recruitment and follow-up criteria have been previously published. ${ }^{19,20} \mathrm{HEPCO}$ recruits participants through street-level strategies and community-program referrals. To be eligible, participants must report having injected drugs within the previous 6 months and be 18 years of age or older. Initially, only HCV-seronegative participants, at risk of primary HCV infection, were recruited. Since 2011, recruitment expanded to include HCV-seropositive, RNA-negative people who inject drugs, who had cleared their infection and were at risk of re-infection. Eligibility for the present study was restricted to HEPCO participants who reported using opioids or taking opioid agonist treatment at least at 1 study visit, and who had a minimum of 2 total visits.

Cohort visits were scheduled at 6-month intervals up to 2011 and at 3-month intervals thereafter, consistent with the need for more frequent testing intervals to assess HCV re-infection. ${ }^{21}$ Visits consisted of answering an interviewer-administered questionnaire and HCV antibody or RNA testing. Participants were asked to return for their test results 2 weeks after each visit for posttest counselling and service referrals. Those who did not report any injection drug use throughout a cumulative period of 24 months were no longer followed. Participants signed an informed consent in compliance with institutional review board regulations of the Centre hospitalier de l'Université de Montréal and received a small stipend (Can\$15-\$20) at each visit.

\section{Measures}

\section{Exposure}

At each visit, participants reported current enrolment in an opioid agonist treatment program (yes/no), prescribed dosage $(\mathrm{mg} / \mathrm{d}$ ) and perceived dosage adequacy (adequate/too low/too high). In line with opioid agonist treatment guidelines for the management of opioid use disorders ${ }^{3,5-7}$ and similar to a previous study, ${ }^{22}$ we categorized a prescribed opioid agonist treatment dosage as "high" if the prescription was methadone $60 \mathrm{mg} / \mathrm{d}$ or greater or buprenorphine (combined with naloxone) $16 \mathrm{mg} / \mathrm{d}$ or greater, and low otherwise. We further stratified perceived dosage adequacy as adequate or inadequate, the latter category being applied to participants who reported their dosage as too high or too low. We assigned each participant to 1 of 5 exposure categories: no opioid agonist treatment, high dosage of opioid agonist treatment perceived to be adequate, high dosage perceived to be inadequate, low dosage perceived to be adequate or low dosage perceived to be inadequate.

In a subanalysis, we replaced high/low categories informed by thresholds specified a priori, with high/moderate/low categories based on tertiles observed in our sample. This categorization was done to examine the presence of a linear trend between prescribed dosage of opioid agonist treatment and HCV infection, and does not reflect clinically indicated thresholds. In Quebec, opioid agonist treatment is subsidized by the provincial public drug benefit program.

\section{Outcome}

The outcome of interest was time to incident HCV infection. Primary infection was defined by the presence of HCV antibodies at a follow-up visit among participants who were previously HCVantibody negative. Blood specimens yielding positive results for HCV antibodies using enzyme immunoassay (Abbott Laboratories) were confirmed by reverse-transcription polymerase chain reaction (Roche Diagnostic Systems). HCV re-infection was defined as a positive HCV-RNA test at a follow-up visit among participants who were previously HCV-RNA negative. RNA testing was performed using the Qualitative COBAS AMPLICOR Test version 2.0 until 2013, and the COBAS Ampliprep/COBAS TaqMan Quantitative Test version 2.0 (Roche) or the RealTime HCV assay (Abbott) thereafter.

\section{Covariates}

We identified potential confounding variables based on previous studies examining the relation between opioid agonist treatment and HCV infection. ${ }^{23}$ These included age (yr), sex (male/female), college education (yes/no), injecting duration (yr), past-month cocaine injection (yes/no), past-month unstable housing, past 3- or 6-month incarceration (depending on follow-up period), and previous HCV infection. As previously, ${ }^{24}$ unstable housing was defined as living on the street, in shelters or in apartment hotels rented on a monthly basis. Because access to opioid agonist treatment and risk of HCV infection might have changed over time, we also considered followup period (2004-2011 v. 2011-2017) as potentially confounding. Opioid injection and injection frequency are postulated to mediate the relation between opioid agonist treatment and risk of HCV infection and were therefore not considered as confounders.

\section{Statistical analysis}

For all participants, follow-up started at the first visit at which opioid use or opioid agonist treatment exposure was reported (henceforth, considered baseline) and ended at the time of HCV infection or, alternatively, at the last visit. We estimated the date of HCV infection using the midpoint between the last negative and first positive HCV test.

We first plotted Nelson-Aalen estimators of the cumulative hazard of HCV infection stratified by dosage of opioid agonist treatment. Suitable for a graphic representation of the effects of time-varying exposures, the plot illustrates the estimated number of times one could theoretically acquire HCV during a given period. ${ }^{25,26}$ At each time point, the relative risk of HCV infection across any 2 exposure categories can be estimated. Second, we employed time-varying Cox regression models to estimate hazard ratios (HRs) and corresponding 
95\% confidence intervals (Cls) of associations between dosage of opioid agonist treatment and risk of HCV infection.

A multivariable model was fit, adjusting for injecting duration and sex as a priori confounders, plus any factors identified as potentially confounding, based on a $5 \%$ change-in-estimate criterion. ${ }^{27}$ With the exception of sex, education and previous HCV infection, we updated all variables at each visit to reflect the most recent information recorded. The linearity assumption for Cox regression was evaluated by plotting martingale residuals for continuous variables. ${ }^{28}$ Both age and duration of injection drug use appeared to be linearly related to HCV infection risk and were therefore analyzed in continuous form. Because of correlation between age and injecting duration (Pearson correlation coefficient, $r=0.70$ ), only the latter was included in the multivariable model. Missing data were infrequent $(<0.5 \%$ for any one variable) and were imputed by the median and modal values for continuous and categorical variables, respectively. Given that it was relatively uncommon for participants to perceive their dosage of opioid agonist treatment as too high if it was perceived to be inadequate (19.7\%), we performed subanalyses excluding these observations to aid interpretation. Statistical analyses were performed using SAS version 9.3.

Although no statistical power calculations were conducted for this investigation when designing the HEPCO cohort, we regularly conduct power calculations for key determinants of HCV infection risk. Assum- ing a sample size of 500 participants and an $80 \%$ annual retention, we estimated having adequate power (> 80\%) to detect significant associations ( 2 -sided $p<0.05$ ) for moderate binary effects (e.g., $\mathrm{HR} \geq 1.4$ ).

\section{Ethics approval}

The objectives of this study fall within the broader goals of HEPCO, which was approved by the institutional review board of the Centre hospitalier de l'Université de Montréal.

\section{Results}

Between November 2004 and August 2017, we recruited 780 people who inject drugs, of whom 604 (77.4\%) reported having used opioids or receiving opioid agonist treatment at least at 1 study visit. Of these, 513 (84.9\%) completed a minimum of 2 visits and made up our study sample. We found no significant differences between participants who did $(n=513)$ and did not $(n=91)$ have a minimum of 2 visits for most variables, including opioid agonist treatment dosage, except for age and prior HCV infection: participants with at least 2 visits were older (median age $35.0 \mathrm{yr}$ v. $29.0 \mathrm{yr}, p<0.01$ ) and more likely to have been infected with HCV previously (30.8\% v. $19.8 \%, p=0.03)$.

The baseline characteristics of participants, overall and stratified by categories of opioid agonist treatment dosage, are presented in Table 1 . Most were male (77.6\%), with a median age of

Table 1: Baseline characteristics of people who inject drugs enrolled in the Montreal Hepatitis C Cohort (2004-2017), by prescribed dosage of opioid agonist treatment, categorized according to clinical guideline recommendations* and patientperceived dosage adequacy

Dosage of opioid agonist treatment and perceived adequacy; no. (\%) of participants $†$

\begin{tabular}{|c|c|c|c|c|c|c|}
\hline Characteristic & $\begin{array}{l}\text { Not enrolled in } \\
\text { opioid agonist } \\
\text { treatment } \\
n=354\end{array}$ & $\begin{array}{l}\text { High dosage, } \\
\text { perceived } \\
\text { adequate } \\
n=61\end{array}$ & $\begin{array}{l}\text { High dosage, } \\
\text { perceived } \\
\text { inadequate } \\
n=25\end{array}$ & $\begin{array}{l}\text { Low dosage, } \\
\text { perceived } \\
\text { adequate } \\
n=49\end{array}$ & $\begin{array}{l}\text { Low dosage, } \\
\text { perceived } \\
\text { inadequate } \\
n=24\end{array}$ & $p$ value $\ddagger$ \\
\hline Age, yr, mean $( \pm S D)$ & $35.8( \pm 10.8)$ & $39.5( \pm 10.7)$ & $38.4( \pm 9.6)$ & $34.9( \pm 9.7)$ & $32.3( \pm 7.9)$ & 0.02 \\
\hline Age, yr, median (IQR) & $33.9(26.9-44.3)$ & $40.7(31.1-47.3)$ & $37.5(32.2-43.0)$ & $33.3(27.4-42.3)$ & $31.3(26.7-35.6)$ & 0.03 \\
\hline Sex, male & $284(80.2)$ & $43(70.5)$ & $16(64.0)$ & $36(73.5)$ & $19(79.2)$ & 0.3 \\
\hline College education or higher & $74(20.9)$ & $22(36.1)$ & $10(40.0)$ & $13(26.5)$ & $11(45.8)$ & $<0.01$ \\
\hline $\begin{array}{l}\text { Duration of injection drug use, yr, } \\
\text { mean }( \pm S D)\end{array}$ & $11.0( \pm 10.2)$ & $18.2( \pm 9.4)$ & $16.5( \pm 11.5)$ & $13.4( \pm 9.9)$ & $11.6( \pm 8.8)$ & $<0.01$ \\
\hline $\begin{array}{l}\text { Duration of injection drug use, yr, } \\
\text { median (IQR) }\end{array}$ & $7.8(2.8-16.2)$ & $18.0(10.1-26.1)$ & $15.0(4.7-25.0)$ & $12.3(4.6-20.3)$ & $9.7(4.0-16.1)$ & $<0.01$ \\
\hline Opioids injection, past mo & $260(73.4)$ & $33(54.1)$ & $22(88.0)$ & $37(75.5)$ & $22(91.7)$ & $<0.01$ \\
\hline Cocaine injection, past mo & $191(54.0)$ & $28(45.9)$ & $8(32.0)$ & $25(51.0)$ & $11(45.8)$ & $<0.01$ \\
\hline $\begin{array}{l}\text { High frequency of injection drug } \\
\text { use ( } \geq 30 \text { injections), past mo }\end{array}$ & $208(58.8)$ & $20(32.8)$ & $13(52.0)$ & $22(44.9)$ & $19(79.2)$ & $<0.01$ \\
\hline Unstable housing, past mo & $147(41.5)$ & $16(26.2)$ & $4(16.0)$ & $8(16.3)$ & $7(29.2)$ & $<0.01$ \\
\hline Incarceration, past 3 or 6 mo§ & $76(21.5)$ & $12(19.7)$ & $5(20.0)$ & $9(18.4)$ & $7(29.2)$ & 0.9 \\
\hline Previous HCV infection & $76(21.5)$ & $34(55.7)$ & $14(56.0)$ & $25(51.0)$ & $9(37.5)$ & $<0.01$ \\
\hline $\begin{array}{l}\text { 2004-2011 follow-up wave } \\
\text { (v. 2011-2017) }\end{array}$ & $199(56.2)$ & $21(34.4)$ & $12(48.0)$ & $27(55.1)$ & $10(41.7)$ & 0.02 \\
\hline
\end{tabular}


Table 2: Hazard ratios for associations between incident hepatitis C virus infection and prescribed dosage of opioid agonist treatment, categorized according to clinical guideline recommendations* and patient-perceived dosage adequacy

\begin{tabular}{|c|c|c|c|c|c|c|}
\hline Variable & $\begin{array}{c}\text { No. of } \\
\text { observations }\end{array}$ & $\begin{array}{l}\text { No. of } \\
\text { person- } \\
\text { years of } \\
\text { follow-up }\end{array}$ & $\begin{array}{l}\text { No. of } \\
\text { incident } \\
\text { cases }\end{array}$ & $\begin{array}{c}\text { Rate per } \\
100 \\
\text { person- } \\
\text { years }\end{array}$ & $\begin{array}{l}\text { Unadjusted HR } \\
\qquad(95 \% \mathrm{Cl})\end{array}$ & $\begin{array}{l}\text { Adjusted HR† } \\
(95 \% \mathrm{CI})\end{array}$ \\
\hline \multicolumn{7}{|c|}{ Dosage of opioid agonist treatment and perceived adequacy } \\
\hline Not enrolled in opioid agonist treatment & 1831 & 782.78 & 118 & 15.07 & 1.00 (Ref.) & 1.00 (Ref.) \\
\hline High dosage, perceived adequate & 663 & 274.07 & 10 & 3.65 & $0.28(0.15-0.54)$ & $0.43(0.23-0.84)$ \\
\hline High dosage, perceived inadequate & 214 & 86.28 & 5 & 5.80 & $0.43(0.17-1.05)$ & $0.61(0.25-1.50)$ \\
\hline Low dosage, perceived adequate & 510 & 207.15 & 20 & 9.65 & $0.79(0.49-1.28)$ & $1.22(0.74-2.00)$ \\
\hline Low dosage, perceived inadequate & 211 & 72.32 & 15 & 20.74 & $1.46(0.85-2.50)$ & $1.94(1.11-3.39)$ \\
\hline Age, yr‡§ & & & & & $0.83(0.76-0.90)$ & - \\
\hline$\leq 31.6$ & 856 & 430.95 & 86 & 19.96 & - & - \\
\hline$>31.6-40.4$ & 859 & 375.57 & 39 & 10.38 & - & - \\
\hline$>40.4-48.2$ & 856 & 326.55 & 26 & 7.96 & - & - \\
\hline$>48.2$ & 858 & 289.53 & 17 & 5.87 & - & - \\
\hline \multicolumn{7}{|l|}{ Sex } \\
\hline Female & 664 & 281.18 & 36 & 12.80 & 1.00 (Ref.) & 1.00 (Ref.) \\
\hline Male & 2765 & 1141.41 & 132 & 11.56 & $1.00(0.69-1.45)$ & $0.74(0.50-1.10)$ \\
\hline \multicolumn{7}{|l|}{ College education or higher } \\
\hline No & 2472 & 1062.6 & 140 & 13.18 & 1.00 (Ref.) & - \\
\hline Yes & 957 & 359.99 & 28 & 7.78 & $0.55(0.37-0.82)$ & - \\
\hline Duration of injection drug use, yr $\ddagger$ & & & & & $0.79(0.72-0.87)$ & $0.85(0.77-0.94)$ \\
\hline$\leq 7.2$ & 857 & 399.79 & 91 & 22.76 & - & - \\
\hline$>7.2-15.3$ & 859 & 403.14 & 41 & 10.17 & - & - \\
\hline$>15.3-25.0$ & 856 & 331.85 & 22 & 6.63 & - & - \\
\hline$>25.0$ & 857 & 287.82 & 14 & 4.86 & - & - \\
\hline \multicolumn{7}{|l|}{ Cocaine injection, past mo } \\
\hline No & 2088 & 886.91 & 52 & 5.86 & 1.00 (Ref.) & 1.00 (Ref.) \\
\hline Yes & 1341 & 535.69 & 116 & 21.65 & $3.17(2.28-4.40)$ & $2.85(2.04-3.99)$ \\
\hline \multicolumn{7}{|l|}{ Unstable housing, past mo } \\
\hline No & 2579 & 1075.58 & 88 & 8.18 & 1.00 (Ref.) & 1.00 (Ref.) \\
\hline Yes & 850 & 347.01 & 80 & 23.05 & $2.34(1.72-3.17)$ & $2.14(1.54-2.96)$ \\
\hline \multicolumn{7}{|l|}{ Incarceration, past 3 or 6 mo } \\
\hline No & 3068 & 1245.82 & 121 & 9.71 & 1.00 (Ref.) & 1.00 (Ref.) \\
\hline Yes & 361 & 176.78 & 47 & 26.59 & $2.32(1.65-3.27)$ & $1.80(1.26-2.56)$ \\
\hline \multicolumn{7}{|l|}{ Previous HCV infection } \\
\hline No & 2148 & 972.59 & 138 & 14.19 & 1.00 (Ref.) & 1.00 (Ref.) \\
\hline Yes & 1281 & 450 & 30 & 6.67 & $0.43(0.29-0.64)$ & $0.73(0.46-1.15)$ \\
\hline \multicolumn{7}{|l|}{ Follow-up wave } \\
\hline 2004-2011 & 912 & 551.26 & 96 & 17.41 & 1.00 (Ref.) & - \\
\hline 2011-2017 & 2517 & 871.34 & 72 & 8.26 & $0.64(0.47-0.87)$ & - \\
\hline \multicolumn{7}{|c|}{$\begin{array}{l}\text { Note: } \mathrm{Cl}=\text { confidence interval, } \mathrm{HCV}=\text { hepatitis } \mathrm{C} \text { virus, } \mathrm{HR}=\text { hazard ratio, Ref. = reference category. } \\
\text { ×Prescribed dosage was categorized as high if methadone } \geq 60 \mathrm{mg} / \mathrm{d} \text { or buprenorphine } \geq 16 \mathrm{mg} / \mathrm{d} \text {, and low otherwise.,.5-7 } \\
\text { †Adjusted for sex (male/female), duration of injection drug use (yr), past-month cocaine injection (yes/no), past-month unstable housing (yes/no), past 3- or 6-month incarceration } \\
\text { (yes/no), and previous } \mathrm{HCV} \text { infection (yes/no). } \\
\text { †Age and duration of injection drug use were analyzed in continuous form in Cox regression models. Hazard ratios represent the effect of a 5-year increase. } \\
\text { \$Because of correlation with duration of injection drug use (Pearson correlation coefficient, } r=0.70 \text { ), this variable was not entered in the multivariable Cox regression model. } \\
\text { qDepending on follow-up wave. }\end{array}$} \\
\hline
\end{tabular}


35.0 years and median duration of injection drug use of 9.5 years. Among participants enrolled in opioid agonist treatment $(n=$ 159), 61 (38.4\%) had a high dosage that they perceived to be adequate, $25(15.7 \%)$ had a high dosage perceived to be inadequate, $49(30.8 \%)$ had a low dosage perceived to be adequate, and 24 $(15.1 \%)$ had a low dosage perceived to be inadequate.

The median number of study visits per participant was 6 (interquartile range 3-10). Over a total observation period of 1422.6 person-years of follow-up, 168 participants (32.7\%) acquired HCV, for an incidence rate of 11.8 per 100 person-years (95\% Cl 10.1-13.7).

Table 2 presents crude and adjusted HRs for associations between dosage of opioid agonist treatment and risk of HCV infection relative to no exposure to opioid agonist treatment. We observed a gradient in the relative risk of HCV infection across the 4 categories of opioid agonist treatment dosage. In multivariable analyses, people who inject drugs who had a high dosage of opioid agonist treatment that they perceived to be adequate had the lowest risk of HCV infection (adjusted HR $0.43,95 \% \mathrm{Cl} 0.23-0.84$ ). In those with a high dosage of opioid agonist treatment perceived to be inadequate and with a low dosage perceived to be adequate, the risk of HCV infection was lower (adjusted HR 0.61, 95\% Cl 0.251.50) and slightly higher (adjusted HR 1.22, 95\% Cl 0.74-2.00), respectively, relative to people who inject drugs not receiving opioid agonist treatment, yet these estimates were imprecise and nonsignificant. For those with a low dosage of opioid agonist treatment perceived to be inadequate, the risk of HCV infection was nearly twofold greater (adjusted HR 1.94, 95\% Cl 1.11-3.39) relative to those not receiving opioid agonist treatment.

Results were comparable in subanalyses excluding observations in which opioid agonist treatment dosage was perceived to be too high (data not shown). In subanalyses replacing high/low categories of prescribed opioid agonist treatment dosage with high/moderate/low categories based on tertiles, we noted a linear trend between dosage and risk of HCV infection (Table 3). Nelson-Aalen curves showed a gradient in the cumulative hazard of HCV infection across categories of opioid agonist treatment dosage, mirroring results from Cox regression analyses (Figure 1).

\section{Interpretation}

In our study, we found that, compared with no opioid agonist treatment, exposure to a high dosage of opioid agonist treatment (methadone $\geq 60 \mathrm{mg} / \mathrm{d}$ or buprenorphine $\geq 16 \mathrm{mg} / \mathrm{d}$ ) is associated, on average, with a $60 \%$ lower risk of infection if the dosage is perceived to be adequate. In contrast, relative to no opioid agonist treatment, exposure to a low dosage of opioid agonist treatment is associated with a twofold greater risk of HCV infection if the dosage is perceived to be inadequate. Exposure to a high dosage perceived to be inadequate and a low dosage perceived to be adequate did not significantly influence HCV risk relative to no exposure to opioid agonist treatment. However, taken together, estimates were consistent with a graded effect of prescribed dosage of opioid agonist treatment and patient-perceived dosage adequacy on risk of $\mathrm{HCV}$ infection. Importantly, our findings are indicative of the potential for both protective and harmful effects of opioid agonist treatment dosage, depending on these factors.

The only other study to have compared risk of HCV infection in relation to prescribed dosage of opioid agonist treatment documented a similar reduction in risk for people who inject drugs receiving low (HR 0.58) and high dosages (HR 0.68), relative to those not receiving opioid agonist treatment, yet neither association was significant.22 Data are lacking on the role of patients' perceptions of the dosage adequacy of opioid agonist treatment in HCV prevention among people who inject drugs. However, accumulating evidence supports the role of patients' perceptions of opioid agonist treatment adequacy in driving favourable outcomes, ${ }^{12-14}$ and these are increasingly recognized as a valuable complement to providers' perspectives in defining targets for optimal treatment. ${ }^{29}$

Although our findings suggest that exposure to a high dosage of opioid agonist treatment that is also subjectively perceived as adequate is most likely to confer an HCV-prevention benefit, it remains to be established how to balance clinically recommended dosages with patients' preferences. If a low dosage is perceived to be adequate by patients, and an increase is not desired, the potentially limited benefit to HCV prevention conferred through opioid

Table 3: Hazard ratios for associations between incident hepatitis C virus infection and prescribed dosage of opioid agonist treatment, categorized according to tertiles* and patient-perceived dosage adequacy

\begin{tabular}{|c|c|c|c|c|c|c|}
\hline $\begin{array}{l}\text { Dosage of opioid agonist treatment } \\
\text { and perceived adequacy }\end{array}$ & $\begin{array}{l}\text { No. of } \\
\text { observations }\end{array}$ & $\begin{array}{c}\text { No. of } \\
\text { person-years } \\
\text { of follow-up }\end{array}$ & $\begin{array}{l}\text { No. of } \\
\text { incident } \\
\text { cases }\end{array}$ & $\begin{array}{l}\text { Rate per } 100 \\
\text { person-years }\end{array}$ & $\begin{array}{l}\text { Unadjusted HR } \\
\qquad(95 \% \mathrm{CI})\end{array}$ & $\begin{array}{l}\text { Adjusted HR } † \\
(95 \% \mathrm{CI})\end{array}$ \\
\hline Not enrolled in opioid agonist treatment & 1831 & 782.78 & 118 & 15.07 & 1.00 (Ref.) & 1.00 (Ref.) \\
\hline High dosage, perceived adequate & 390 & 167.10 & 4 & 2.39 & $0.18(0.07-0.50)$ & $0.27(0.10-0.74)$ \\
\hline High dosage, perceived inadequate & 113 & 49.90 & 2 & 4.01 & $0.32(0.08-1.28)$ & $0.37(0.09-1.49)$ \\
\hline Moderate dosage, perceived adequate & 402 & 156.06 & 12 & 7.69 & $0.59(0.32-1.07)$ & $0.93(0.50-1.72)$ \\
\hline Moderate dosage, perceived inadequate & 139 & 49.28 & 6 & 12.18 & $0.83(0.37-1.89)$ & $1.40(0.61-3.24)$ \\
\hline Low dosage, perceived adequate & 381 & 158.05 & 14 & 8.86 & $0.75(0.43-1.31)$ & $1.21(0.68-2.14)$ \\
\hline Low dosage, perceived inadequate & 173 & 59.41 & 12 & 20.20 & $1.42(0.78-2.58)$ & $1.95(1.06-3.59)$ \\
\hline
\end{tabular}



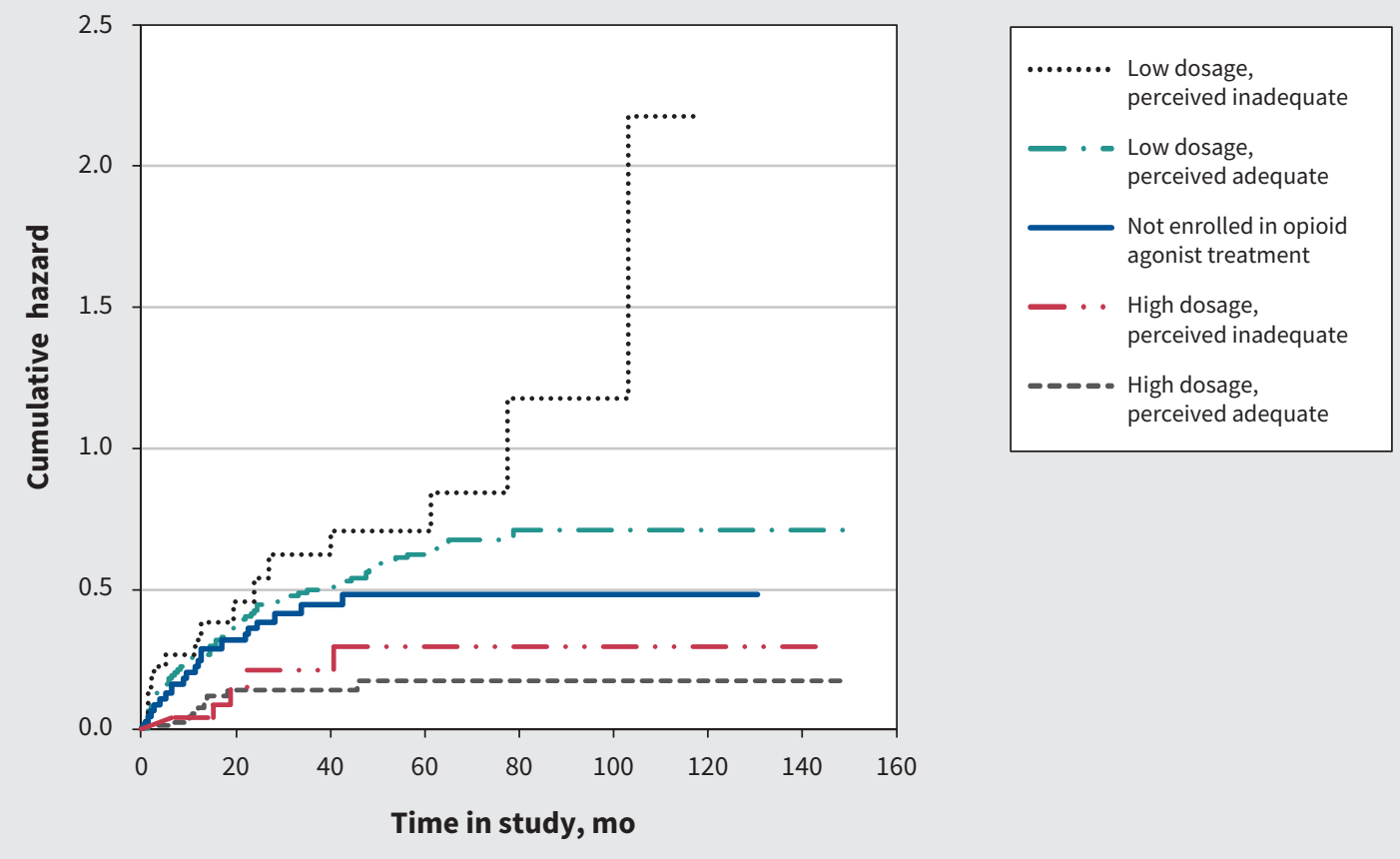

18

8

Figure 1: Nelson-Aalen estimates of the cumulative hazard of hepatitis $C$ virus infection according to prescribed dosage of opioid agonist treatment and patient-perceived dosage adequacy.

agonist treatment should be discussed. Our finding of a nearly twofold greater risk of HCV infection among people who inject drugs receiving a low and subjectively inadequate dosage of opioid agonist treatment, compared with those not enrolled in opioid agonist treatment, is particularly worrisome. For most participants in our study, dosages of opioid agonist treatment that were perceived to be inadequate were reportedly too low. This inadequate dosing could lead to increased illicit drug use and risk behaviours, ${ }^{9}$ potentially explaining the greater risk of HCV infection.

Although further research is needed to explore reasons leading to low or inadequate dosing of opioid agonist treatment, prior studies have flagged social stigma surrounding this treatment ${ }^{14}$ and abstinence-oriented ideologies among prescribers and treatment settings as potential drivers. ${ }^{15}$ Altogether, our study supports the need to ensure that opioid agonist treatment programs provide care following best-practice guidelines and that clinicians work with patients to identify a suitable dosage that is most likely to be clinically effective while meeting their individual needs.

\section{Limitations}

Our study had several limitations. First, residual confounding of the estimated associations cannot be ruled out, despite our efforts to adjust for known confounders. For example, the reduced risk of $\mathrm{HCV}$ infection observed among people who inject drugs whose dosage of opioid agonist treatment was high and perceived to be adequate could be partly attributed to having greater motivation to reduce risk behaviours relative to other participants. Second, selec- tion bias as a result of losses to follow-up may have affected our estimates. Our follow-up rates are good for a population of people who inject drugs, however, and participants lost to follow-up were similar to those retained with respect to most baseline characteristics, diminishing the likelihood of this risk. Third, because it was based on self-report, misclassification of opioid agonist treatment dosage is possible. However, in one study involving people who inject drugs in Amsterdam, authors validated self-reported methadone dosage and found excellent correlation between self-report and prescription registry data. ${ }^{30}$ Finally, our focus on the joint effect of 2 measures of opioid agonist treatment dosage on HCV infection risk may have limited our power to detect significant associations, particularly for the category of high dosages perceived to be inadequate, which had few events.

\section{Conclusion}

Risk of HCV infection varies substantially according to a combined indicator of opioid agonist treatment dosage informed by prescribed dosage and patients' perceptions. Our results suggest that, to benefit from a lower risk of HCV infection while taking opioid agonist treatment, people who inject drugs must be prescribed a high dosage that they also perceive to be adequate. In light of ongoing calls to broaden access to opioid agonist treatment globally to foster elimination of HCV, our findings suggest that simply expanding access may not be enough and that ensuring adequate dosage of opioid agonist treatment should be central to any HCV-prevention strategy. 


\section{References}

1. Zibbell JE, Asher AK, Patel RC, et al. Increases in Acute hepatitis c virus infection related to a growing opioid epidemic and associated injection drug use, United States, 2004 to 2014. Am J Public Health 2018;108:175-81.

2. Bruneau J, Roy E, Arruda N, et al. The rising prevalence of prescription opioid injection and its association with hepatitis $C$ incidence among street-drug users. Addiction 2012;107:1318-27.

3. Bruneau J, Ahamad K, Goyer ME, et al.; CIHR Canadian Research Initiative in Substance Misuse. Management of opioid use disorders: a national clinical practice guideline. CMAJ 2018;190:E247-57.

4. Platt L, Minozzi S, Reed J, et al. Needle and syringe programmes and opioid substitution therapy for preventing HCV transmission among people who inject drugs: findings from a Cochrane Review and meta-analysis. Addiction 2018;113:545-63.

5. Clinical Guidelines on Drug Misuse and Dependence Update 2017 Independent Expert Working Group. Drug misuse and dependence: UK guidelines on clinical management. London (UK): Department of Health; 2017. Available: https://assets .publishing.service.gov.uk/government/uploads/system/uploads/attachment_ data/file/673978/clinical_guidelines_2017.pdf (accessed 2018 June 5).

6. Kampman K, Jarvis M. American Society of Addiction Medicine (ASAM) national practice guideline for the use of medications in the treatment of addiction involving opioid use. J Addict Med 2015;9:358-67.

7. Guidelines for the psychosocially assisted pharmacological treatment of opioid dependence. Geneva: World Health Organization; 2009. Available: www.who.int/substance_ abuse/publications/opioid_dependence_guidelines.pdf (accessed 2018 June 4).

8. Fareed A, Casarella J, Amar R, et al. Methadone maintenance dosing guideline for opioid dependence, a literature review. J Addict Dis 2010;29:1-14.

9. Faggiano F, Vigna-Taglianti F, Versino E, et al. Methadone maintenance at different dosages for opioid dependence. Cochrane Database Syst Rev 2003;(3):CD002208.

10. Fullerton CA, Kim M, Thomas CP, et al. Medication-assisted treatment with methadone: assessing the evidence. Psychiatr Serv 2014;65:146-57.

11. Mattick RP, Breen C, Kimber J, et al. Buprenorphine maintenance versus placebo or methadone maintenance for opioid dependence. Cochrane Database Syst Rev 2004;(3):CD002207.

12. Heikman PK, Muhonen LH, Ojanperä IA. Polydrug abuse among opioid maintenance treatment patients is related to inadequate dose of maintenance treatment medicine. BMC Psychiatry 2017;17:245.

13. Roux P, Lions C, Michel L, et al.; ANRS Methaville Study Group. Predictors of non-adherence to methadone maintenance treatment in opioid-dependent individuals: implications for clinicians. Curr Pharm Des 2014;20:4097-105.

14. Sanders JJ, Roose RJ, Lubrano MC, et al. Meaning and methadone: patient perceptions of methadone dose and a model to promote adherence to maintenance treatment. J Addict Med 2013;7:307-13.

15. D’Aunno T, Pollack HA, Frimpong JA, et al. Evidence-based treatment for opioid disorders: a 23-year national study of methadone dose levels [published erratum in J Subst Abuse Treat 2017;79:75]. J Subst Abuse Treat 2014;47:245-50.
16. Nosyk B, Marsh DC, Sun H, et al. Trends in methadone maintenance treatment participation, retention, and compliance to dosing guidelines in British Columbia, Canada: 1996-2006. J Subst Abuse Treat 2010;39:22-31.

17. Global health sector strategy on viral hepatitis: 2016-2021 - towards ending viral hepatitis. Geneva: World Health Organization; 2016. Available: http:// apps.who.int/iris/bitstream/10665/246177/1/WHO-HIV-2016.06-eng.pdf?ua=1 (accessed 2017 Aug. 18).

18. Martin NK, Hickman M, Hutchinson SJ, et al. Combination interventions to prevent HCV transmission among people who inject drugs: modeling the impact of antiviral treatment, needle and syringe programs, and opiate substitution therapy [published erratum in Clin Infect Dis 2014;58:1203]. Clin Infect Dis 2013;57(Suppl 2):S39-45.

19. Bruneau J, Zang G, Abrahamowicz M, et al. Sustained drug use changes after hepatitis $C$ screening and counseling among recently infected persons who inject drugs: a longitudinal study. Clin Infect Dis 2014;58:755-61.

20. Bruneau J, Arruda N, Zang G, et al. The evolving drug epidemic of prescription opioid injection and its association with HCV transmission among people who inject drugs in Montreal, Canada. Addiction 2019;114:366-73.

21. Vickerman P, Grebely J, Dore GJ, et al.; International Collaboration of Incident HIV and Hepatitis C in Injecting Cohorts (InC3). The more you look, the more you find: effects of hepatitis $C$ virus testing interval on reinfection incidence and clearance and implications for future vaccine study design [published erratum in J Infect Dis 2012;206:624]. J Infect Dis 2012;205:1342-50.

22. Van Den Berg C, Smit C, Van Brussel G, et al.; Amsterdam Cohort. Full participation in harm reduction programmes is associated with decreased risk for human immunodeficiency virus and hepatitis $C$ virus: evidence from the Amsterdam Cohort Studies among drug users. Addiction 2007;102:1454-62.

23. Platt L, Minozzi S, Reed J, et al. Needle syringe programmes and opioid substitution therapy for preventing hepatitis $C$ transmission in people who inject drugs. Cochrane Database Syst Rev 2017;9:CD012021.

24. Artenie AA, Roy É, Zang G, et al. Hepatitis C virus seroconversion among persons who inject drugs in relation to primary care physician visiting: the potential role of primary healthcare in a combined approach to Hepatitis $C$ prevention. Int $J$ Drug Policy 2015;26:970-5.

25. Nosyk B, Min JE, Evans E, et al. The effects of opioid substitution treatment and highly active antiretroviral therapy on the cause-specific risk of mortality among HIV-positive people who inject drugs. Clin Infect Dis 2015;61:1157-65.

26. Munoz-Price LS, Frencken JF, Tarima S, et al. Handling time-dependent variables: antibiotics and antibiotic resistance. Clin Infect Dis 2016;62:1558-63.

27. Rothman KJ, Greenland S, Lash TL. Modern epidemiology. 3rd ed. South Holland (the Netherlands): Wolters Kluwer; 2012.

28. Kleinbaum DG, Klein M. Survival analysis. New York: Springer; 1996

29. Trujols J, Siñol N, Iraurgi I, et al. Patient and clinician's ratings of improvement in methadone-maintained patients: Differing perspectives? Harm Reduct J 2011;8:23.

30. Langendam MW, van Haastrecht HJ, van Ameijden EJ. The validity of drug users' self-reports in a non-treatment setting: prevalence and predictors of incorrect reporting methadone treatment modalities. Int J Epidemiol 1999;28:514-20.
Competing interests: Julie Bruneau received honoraria from Gilead Sciences and from Merck for participating in advisory meetings, and a grant from Gilead Sciences, outside of the current work, in relation to hepatitis $C$ virus treatment for people who use drugs. Didier Jutras-Aswad reports nonfinancial support (study material for a randomized controlled trial) from Insys Therapeutics. All other authors report no potential conflicts.

This article has been peer reviewed.

Affiliations: Department of Social and Preventive Medicine (Artenie, Minoyan, Gauvin), School of Public Health, Université de Montréal; Research Centre (Artenie, Minoyan, Jacka, Høj, Jutras-Aswad, Gauvin, Zang, Bruneau), Centre Hospitalier de l'Université de Montréal; Department of Psychiatry (Jutras-Aswad), Université de Montréal, Montréal, Que.; Addiction Studies and Research Program (Roy), Université de Sherbrooke, Longueuil, Que.; Institut national de santé publique du Québec (Roy); Department of Family and Emergency Medicine (Bruneau), Université de Montréal, Montréal, Que.

Contributors: Andreea Artenie and Julie Bruneau conceptualized and designed the study. Andreea Artenie conducted the statistical analyses, with guidance from Geng Zang, and drafted the first version of the manuscript. Julie Bruneau, Didier Jutras-Aswad and Élise Roy were co-principal investigators of the Montreal Hepatitis C Cohort study at the time of this study. All of the authors contributed to the interpretation of data and critical revisions of the manuscript for important intellectual content. All of the authors gave final approval of the version to be published and agreed to be accountable for all aspects of the work.

Funding: This work was supported by the Canadian Institutes of Health Research (CIHR) (grants MOP135260 and MOP210232) and the Réseau Sida et Maladies Infectieuses du Fonds de recherche du Québec - Santé (FRQ-S) (grant FRSQ5227). Andreea Artenie is supported through a CIHR Doctoral Award (Frederick Banting and Charles Best Canada Graduate Scholarships) and a Canadian Network on Hepatitis C (CanHepC) PhD fellowship. Nanor Minoyan is supported through a CanHepC PhD fellowship. Brendan Jacka is supported through FRQ-S and CanHepC postdoctoral fellowships. Stine Høj is supported through a CanHepC postdoctoral fellowship. Didier Jutras-Aswad holds a clinical research career award from FRQ-S. Élise Roy holds the Research Chair in Drug Addiction funded by the Charles LeMoyne Hospital Foundation, and the Faculty of Medicine and Health Sciences, Université de Sherbrooke.

Acknowledgements: The authors thank Rachel Bouchard, Élisabeth Deschênes, Marie-Eve Turcotte, Maryse Beaulieu and the other staff working at the HEPCO research site. We also thank the study participants; without them, this research would not be possible.

Accepted: Mar. 29, 2019

Correspondence to: Julie Bruneau, julie.bruneau@umontreal.ca 